\title{
Report: Developing the Guideline of Therapeutic Interventions for Street Children With Substance Use Disorders
}

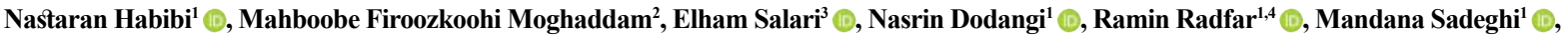

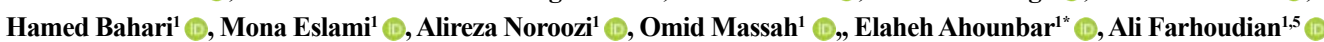

1. Substance Abuse and Dependence Research Center, University of Social Welfare and Rehabilitation Sciences, Tehran, Iran.

2. Research Center for Children and Adolescents Health, Zahedan University of Medical Sciences, Zahedan, Iran

3. Department of Psychiatry, School of Medicine, Mashhad Branch, Islamic Azad University, Mashhad, Iran.

4. UCLA Integrated Substance Abuse Programs, University of California, Los Angeles, California, United States.

5. Department of Psychiatry, School of Medicine, Tehran University of Medical Sciences, Tehran, Iran.

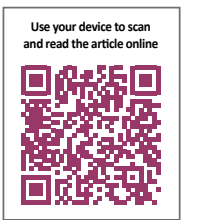

Citation Habibi N, Firoozkoohi Moghaddam M, Salari E, Dodangi N, Radfar R, Sadeghi M, Bahari H, et al. Developing the Guideline of Therapeutic Interventions for Street Children With Substance Use Disorders. Iranian Rehabilitation Journal. 2018; 16(4):425-432. http://dx.doi.org/10.32598/irj.16.4.425

doi" http://dx.doi.org/10.32598/irj.16.4.425

\section{(1) (9)}

Article info:

Received: 14 May 2018

Accepted: 25 Sep 2018

Available Online: 01 Dec 2018

Keywords:

Therapeutic interventions, Street children, Substance use disorders

\begin{abstract}
A B STRACT
Millions of children are left to survive on the streets around the world. Investigations on drug use disorders among street children reveal that they not only abuse all types of drugs higher than their peers who live at home or in shelters, but also they abuse more harmful drugs such as injection drugs or methamphetamines. This guideline provides a comprehensive approach to the treatment and management of substance use disorders among children of 3 to 18 years of age for the staff of substance use disorder clinics. It highlights examples of how to perceive and approach the management and issues of substance abuse among street children at an early stage of development through various medical, psycho-social, and other interventions. It also defines the characteristics of the street children with a focus on prevention. These provisions consist of addressing the applicability matters in this area and necessity of a decision model in our country.
\end{abstract}

\section{Highlights}

- This guideline provides a comprehensive approach for the management of substance use disorders among children.

- It highlights examples for the early management of substance abuse among street children.

- It also defines the characteristics of street children with a focus on prevention programs.

\section{Plain Language Summary}

Millions of children are left to survive in the streets worldwide. Street children abuse not only all types of drugs, but also more harmful drugs such as injection drugs or methamphetamines. This guideline provides a comprehensive approach for the management of substance use disorders among children of 3 to 18 years old for the staff of substance use disorder clinics. It also defines the characteristics of the street children with a focus on prevention, which could be helpful for policy makers.

\section{* Corresponding Author:}

Elaheh Ahounbar, $M A$.

Address: Substance Abuse and Dependence Research Center, University of Social Welfare and Rehabilitation Sciences, Tehran, Iran.

Tel: +98 (21) 22180097

E-mail: e.ahounbar@yahoo.com 


\section{Introduction}

ased on the United Nations International Children's Emergency Fund (UNICEF)

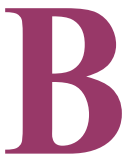
reports, millions of children are left to survive on the streets around the world [1] They are forced to work and live on their own without fulfilling their essential needs such as food, housing, social security, affection, and education, which not only leads to a vulnerable living and an extremely inadequate biopsychosocial care [2], but also lures them into drug abuse in order to cope with their challenging living and to survive on the streets [3]. In such cases, "the non-medical use of chemical substances in order to achieve alterations in psychological functioning has been termed as substance use". [4]. According to UNICEF surveys in 2002, the number of street children was about 100 million [5].

There are some helpful factors in identifying intervention areas for street children in order to prevent further damages to their lives, and possibly reducing their number. Such factors consist of studying the psychopathology and its affecting elements in this regard. Street children mostly visit Non-Governmental Organizations (NGOs), seeking needs like eating, bathing and medical care. NGOs assist thousands of street children with various programs, which are good opportunities to reach a better assessment of vulnerability to various psychological disorders among them and improve interventions and prevent further problems in their lives [6].

The key findings of prior investigations on drug use disorders among street children was that the rate of all types of drugs abused by this population is higher than their peers who live at home or in shelters. In addition, they abuse more harmful drugs like injection drugs or methamphetamines. Such high prevalence of substance abuse necessitates the provision of adequate management for adolescents who live on the streets [7-9]. Based on the studies, poverty, child abuse and neglect, and family breakdown are the major causes of the problem [10]. Thus, this guideline was developed to assist in the prevention, harm reduction and treatment interventions of opioid abuse among the street children of 3-18 years of age. It was hypothesized that using this guideline could facilitate effective actions in the target society.

The literature review reveals an available guideline on the same area of subject in Iran [11]. Some authors have also developed the typology of street substance users' communities in Iran and highlighted the necessity of modifying provided harm reduction services, according to these communities [12]. In addition, the guidelines of other countries literally do not address the specific needs of Iranian population. The process of developing an opioid harm reduction guideline for street children aged 3-18 started with an oversees committee who advised on the development of substance abuse harm reduction guidelines. The committee members included representatives from relevant organizations in substance abuse, university professors, and experts in substance use disorders.

A draft of guideline was initially prepared based on the recommendations of Ministry of Health and Medical Education of Iran and UNICEF counseling. The final draft was presented after applying comments of various children service provides, clinicians and social workers. This guideline is presented before any pilot interventions and shall be updated and revised based on the administration results. This is only used as an implementation basis to represent various services in a comprehensive format and the results will be determined after implementation.

\section{Target Population}

This guideline provides a comprehensive approach to the treatment and management of substance use disorders among children of 3 to 18 years of age for the staff of substance use disorder clinics who provide services to opioid dependent children. It is also applicable for the all groups of healthcare providers to children ages 18 years and younger, including governmental and NGOs supporting street children, social welfare organizations, staff of the children shelters, municipal administrators, and any street children care authorities, in general.

\section{Guideline Development Process}

The guideline committee followed a well-defined process for its development, based on a systematic review of the literature on substance abuse disorders for street children. The guideline was organized in steps like choosing the topic of the proposal to dissemination and implementation process, as follows: 1. Form a systematic review author panel; 2. Develop clinical questions; 3. Review the literature; 4. Hold focus group discussion sessions; 5. Summarize the obtained evidence; 6 . Organize expert panels; 7. Draft the protocol and consider professional comments; 8. Employ the recommendations; and 9. Finally stage establish a dedicated clinic for pilot implementation/practice of the guideline by Substance Abuse and Dependence Research Center, University of Social Welfare and Rehabilitation Sciences, which has not been performed yet. The manual is considered a dynamic document that could be updated by the scientific com- 
mittee as needed. Therefore, it is designed rigorously to evaluate the strength of the evidence and formulate explicit practice recommendations to improve treatment and management outcomes.

\section{Literature Review}

To some extent, the literature review was an additional step, because there were no existing guidelines on the subject. Thus, the committee conducted an article review, to create a framework about the project and reach an up-to-date knowledge of the relevant work of others. We searched the entire history of the field, and not only a particular period of time. However, there were not many studies on the topic. Therefore, we decided to expand the review on various topics related to the street children, in order to realistically 'address a gap', rather than 'fill a gap'. The review objectives were to identify necessary services and programs on the street children. We have outlined interventions in detail to empower all affecting factors with better management services for those children.

\section{Guideline Committee Meetings}

The process of developing this guideline was a joint venture between the Substance Abuse and Dependence Research Center, University of Social Welfare and Rehabilitation Sciences and Ministry of Health and Medical Education of Iran. All committee members involved literature review in the area of their own specialty, and shared the results with other members. In addition, they all collaborated on establishing the "substance abuse disorders treatment clinic for minors" and were appointed duties there. Meanwhile, a subcommittee was in charge of coordinating and scheduling the qualitative studies and field visits. A subgroup consisted of professionals to contribute on the social work package. Another subcommittee administered the prevention, treatment and harm reduction package. Guideline committee chairs carried the key responsibility of observing committee work thorough and communicated with the guideline committee leadership.

The guideline officers and executive committee supported the objectives by micromanaging the process. The method of how the committee chairs have led the committee and supported when required were as follows: Provided general instructions about committee function and designed and processed a questionnaire consisting of the demographic data of subjects, and risk factors and protecting factors prior to the establishment of "substance abuse disorders treatment clinic for minors". Budgets were adopted by the UNICEF committee after discussion with the executive committee. General plans for committees were approved by the Substance Abuse and Dependence Research Center. Committees reported their actions orally or in written, through regular scheduled meeting, and finally when the project was finalized.

Most of the committee's reporting took place via e-mail, with the occasional in person meetings of subgroups and monthly meetings with all members. The executive staff provided lists of subjects or brief reports if applicable, to facilitate communication among the members.

\section{Clinical Recommendations}

The guideline consists of 3 parts and several sections. First part "substance abuse prevention interventions among street children" is published as a manual for the prevention interventions of substance abuse among street children. It contains specific intervention recommendations. Sections of the first part include background, definitions and risk factors for becoming a street child; "general substance abuse prevention principles" which discusses the management and considerations for prevention plans as those apply to all children in general and street children specifically whom may be at the risk for substance abuse.

Another section features "assessments and clinical treatment" and explains the implementation of a treatment plan and discusses a range of clinical formulations that leads to a clinical intervention algorithm (Figure 1). Also, the "intervention" section recommends some alternative methods and various effective interventions for the street children. This section provides detailed assessments, like the diagnosis of comorbid psychiatric or medical disorders, and necessary family, school and mentoring interventions. Eventually, intervention manuals for shelter home for street children and personal and social skills educations are discussed respectively.

The second part "the assessment and treatment of substance abuse disorders among the street children" underlies an overview of screening, assessment, treatment planning, pharmaceutical treatments, psychological interventions, social support and the management of psychiatric and medical comorbid disorders. Third part "harm reduction manual for substance abuse disorders among the street children" summarizes the definitions, necessities, and general relevant points. It also provides a comprehensive harm reduction manual

Part 1. Substance abuse prevention interventions for street children

Considering different groups of street children, specific and distinct plans were required for each group of them. Therefore, an algorithm was designed in the aim of ordering all treatments, relevant organizations and profes- 
sional comments (Figure 1). The algorithm provided different circumstances and the suggested treatment in order to gain the best possible preventive actions (Figure 1).

Consequently, next step is to conduct a wide assessment to achieve precise information regarding parents and the child himself/herself. This step covers socioeconomic situation, comorbid disorders, and histories of domestic violence, child abuse, sexual orientation, substance abuse disorders and so on. Children who work and live on the street are heterogeneous with regard to a number of clinical features. Care of street children includes a complete psychiatric and biopsychosocial functioning assessment.

\section{Early recognition}

This section summarizes primary prevention interventions, which aimed at children who have not been living on the street for too long and not abandoned by family and still in touch with their family and/or school. The goal is to reduce the harmful factors and focus on residential or rehabilitative care. The guideline suggests a "mobile outreach" team for such interventions.

\section{Family interventions}

Some aspects such as educating the shelter home staff about communicating with the child to endorse him for going back home; educating social workers in family assessments and facilitating the "family reunion" and follow-ups and educating psychologists on family therapy interventions could be useful in the successful reunion of child-family and improving family protection in substance use prevention among street children.

\section{Assessing the provided interventions}

Considering the aforementioned various prevention methods for substance abuse among street children, the following suggestions are helpful on increasing the quality of services provided: Preparing manual and making standard implementation to provide equal and optimal services to different professionals, Determining evaluation indicators and specifying the goals of executing programs, Collecting sufficient data for evaluating the program implementation, and Using appropriate data analysis methods. These evaluation steps aid professionals to realize the deficiencies and meet the predicted goals.
Part 2. Treatment of substance abuse disorders among street children

\section{Screening}

Global Appraisal of Individual Needs (GAIN) questionnaire is a screening tool used for the diagnosis and treatment planning of patients $\geq 12$ years of age. It could be used in outpatient settings, different types of in-patient treatments and methadone maintenance treatment.

\section{Assessment}

The ultimate goal of assessment is to determine the most appropriate treatment plan with the co-operation of the child. The assessment is comprehensive and focuses on all aspects of child's life, such as biopsychological health factors, available social support and any potential effective factor on the treatment.

\section{Treatment planning}

Individuals should be treated in the most confidential setting, based on a comprehensive assessment. Except primary intervention programs, decisions regarding the site of care should be written based on each child's comprehensive assessment data, his/her particular advantages, willingness and capacity to cooperate, and preference for a particular treatment. The treatment plan must be structured according to the issues in child's lifetime history which should consider gender and age, in a caring, respectful and safe environment. Specific treatments must be dedicated to children with substance abuse disorders. In addition, it is essential to frame treatment plans with achievable goals and time schedules.

\section{Pharmaceutical interventions}

Treatment goals are to achieve maintenance to facilitate the prevention of withdrawal states, lapses and overdoses. The types of pharmacological treatments are decided in accordance with the individuals' past history of substance abuse and treatment goals.

\section{Psychosocial interventions}

The main targets of psychosocial interventions consist of increasing the effectiveness of pharmacotherapy, achieving maintenance, changing their lifestyle and improving the quality of their lives. Psychosocial interventions are categorized as either with or without a therapist. The first category could be delivered in short-term (1-4 sessions) or long-term (5-12 sessions), in the form of individual or group psychotherapies. 


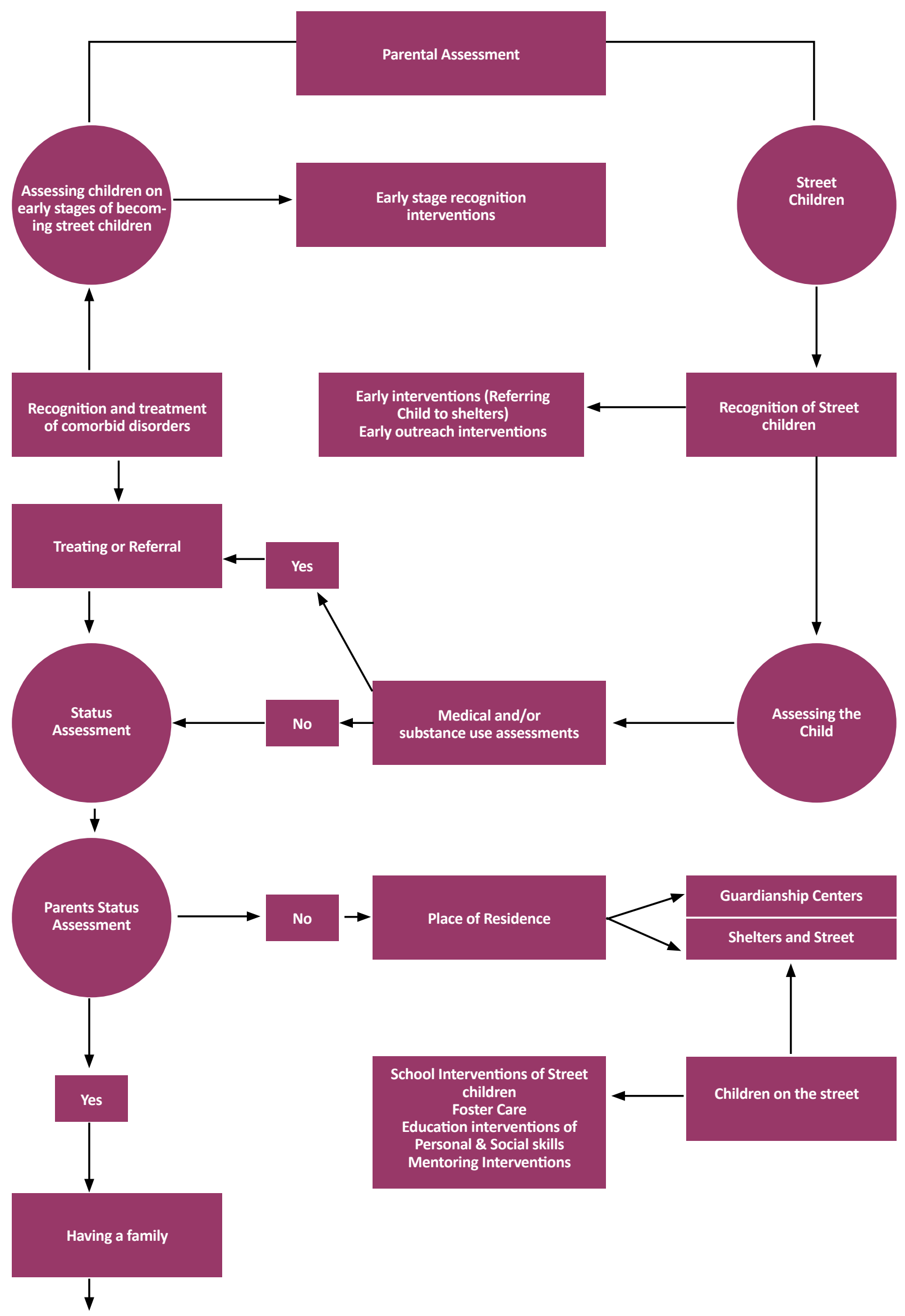




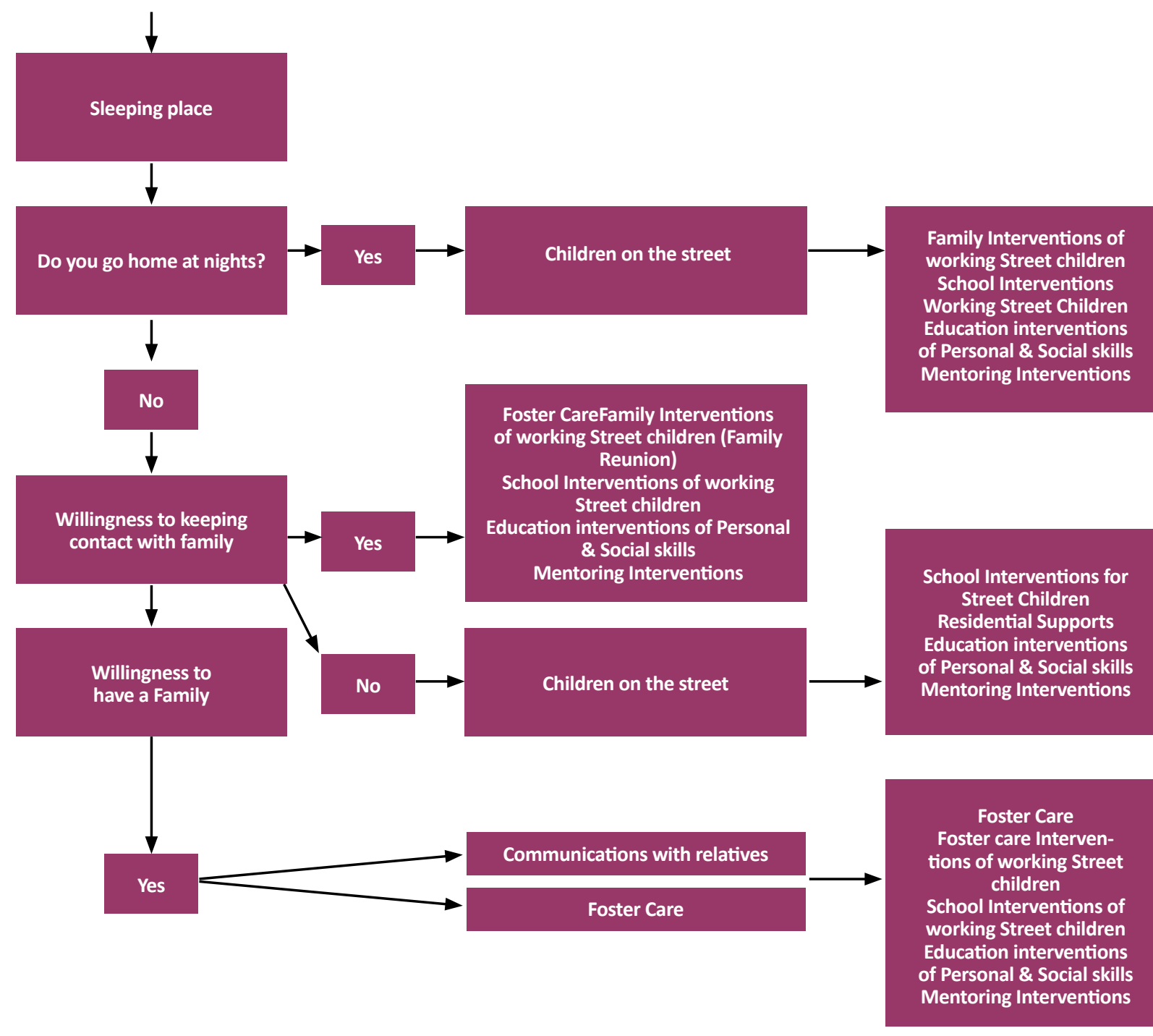

Figure 1. Intervention algorithm for street children

IIranian Rehabilitation Journal

\section{Social support}

Street children are faced with various issues such as substance abuse, sexually transmitted diseases (e.g. HIV/AIDS), and fertilizing problems. Given that numerous personal and social factors evolve arousing such issues, appropriate care must be given to each level of such issues. Types of treatment provided by the professionals depend on the environmental situation, availability of sources, cultural norms and society expectations. Therefore, a comprehensive program is required to meet child's needs in all aspects. Three different treatment levels address personal, social, and other needs.

\section{General medical comorbid disorders}

Children are at risk of various medical conditions including diabetes, asthma, obesity and infections, which in fact require appropriate assessment and treatment.
Common problems among street children are lack of necessary nutrition and different types of injuries. The guideline explains general medical conditions and the treatments for street children, in details.

\section{Psychiatric comorbid disorders}

Substance abuse disorders often co-occur with psychiatric disorders in children and exacerbate their condition. Tendency toward psychoactive substances in children could initiate psychiatric disorders. Moreover, such disorders could highly affect the treatment process. Meanwhile, the comorbidity of psychiatric disorders in children leads to higher treatment withdrawal and poor treatment outcomes in long term. 
Part 3. Harm reduction manual for substance abuse disorders among street children

Harm reduction approaches are literally practical, effective, safe, evidence-based and cost-effective. Most harm reduction approaches are inexpensive and easy to implement.

\section{Comprehensive manual of harm reduction}

To reduce the rapid spread of HIV among substance users and prevent its transmission to the public, an effective and evidence-based action is required. In order to achieve these goals and according to the United Nations Office on Drugs and Crime, the World Health Organization and the United Nations Program on AIDS, the implementation of "the comprehensive package" including 9 stages of interventions for the prevention and treatment of HIV among injection drug abusers is necessary. This package is also known as "harm reduction package" and includes scientifically approved and effective interventions in the prevention of HIV spread.

\section{Guideline applicability issues}

The guideline provides clarification and guidance on the management of substance use among street children. The guideline is designed for the use of professionals and staff in care of street children, to better understand the substance abuse among street children, their requirements and how to meet their demands. The practice must be delivered only as per guidelines and adherence to them may yield successful outcomes for individuals. However, they must not be misinterpreted as including all methods of care. Also, other approved methods of care for the same population must not be overlooked. The ultimate treatment plan must be made by considering the individual's history and conditions and the available options.

\section{Conclusion}

The guideline provides examples of how to perceive and approach the management and issues of substance abuse among street children at an early stage of development, through various biopsychosocial and other interventions. It also defines the characteristics of the street children with a preventive focus. These guidelines consist of addressing the applicability matters in this area and necessity of a decisive model in Iran. The management of neonatal abstinence syndrome is excluded from the scope of the guideline.

\section{Ethical Considerations}

\section{Compliance with ethical guidelines}

The development of guideline was approved by the Ethics Committee of the University of Social Welfare and Rehabilitation Sciences, Tehran, Iran.

\section{Funding}

This guideline was prepared in the Substance Abuse and Dependence Research Center, University of Social Welfare and Rehabilitation Sciences and with the financial supports of UNICEF office in Iran.

\section{Authors contributions}

All authors contributed in preparing this article.

Conflict of interest

The authors declared no conflict of interest.

\section{References}

[1] UNICEF. [The condition of childhood in the world 2007 (Italian)]. New York: UNICEF; 2006.

[2] Ayuku DO, Kaplan C, Baars H, De Vries M. Characteristics and personal social networks of the on-the-street, of-the-street, shelter and school children in Eldoret, Kenya. International Social Work. 2004; 47(3):293-311. [DOI:10.1177/0020872804041428]

[3] Towe VL, ul Hasan S, Zafar ST, Sherman SG. Street life and drug risk behaviors associated with exchanging sex among male street children in Lahore, Pakistan. Journal of Adolescent Health. 2009; 44(3):222-8. [DOI:10.1016/j.jadohealth.2008.09.003] [PMID] [PMCID]

[4] Gowers S. Adolescent Psychiatry in Clinical Practice. Routledge: Taylor \& Francis; 2000.

[5] Bellamy C. The state of the world's children 2002. New York: UNICEF; 2002.

[6] Tacon P. Executive director child-hope: The international movement on behalf of street children. Annual Report; 1987.

[7] Greene JM, Ennett ST, Ringwalt CL. Substance use among runaway and homeless youth in three national samples. American Journal of Public Health. 1997; 87(2):229-35. [DOI:10.2105/AJPH.87.2.229] [PMID] [PMCID]

[8] Kipke MD, Montgomery SB, Simon TR, Iverson EF "Substance abuse" disorders among runaway and homeless youth. Substance Use \& Misuse. 1997; 32(7):969-86 [DOI:10.3109/10826089709055866] 
[9] Greene JM, Ringwalt CL. Youth and familial substance use's association with suicide attempts among runaway and homeless youth. Substance Use \& Misuse. 1996; 31(8):1041-58. [DOI:10.3109/10826089609072286] [PMID]

[10] United Nations Office on Drugs and Crime. Egypt street children report. Vienna: United Nations Office on Drugs and Crime; 2001.

[11] Maarefvand M, Daneshmand R, Shariatirad S, Massah O, Noroozi A, Hashemian SS, et al. Social work guidelines for street children with substance use disorders. Iranian Rehabilitation Journal. 2015; 13(4):120-6.

[12] Maarefvand M, Shirazi MS, Peyravi R, Farhoudian A. Typology of street substance users' communities in Tehran, Iran. Addiction \& Health. 2017; 9(1):32-9. [PMID] [PMCID] 